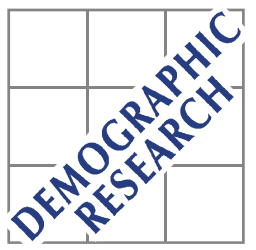

Demographic Research a free, expedited, online journal of peer-reviewed research and commentary in the population sciences published by the Max Planck Institute for Demographic Research Doberaner Strasse 114 D D-18057 Rostock · GERMANY www.demographic-research.org

DEMOGRAPHIC RESEARCH

VOLUME 7, ARTICLE 5, PAGES 271-306

PUBLISHED 06 AUGUST 2002

www.demographic-research.org/Volumes/Vol7/5/

DOI: $10.4054 /$ DemRes.2002.7.5

Research Article

\title{
The Cancer Transition in Japan since 1951
}

\section{Omer Gersten}

John R. Wilmoth

(C) 2002 Max-Planck-Gesellschaft. 


\section{Table of Contents}

$\begin{array}{lll}1 & \text { Introduction } & 272\end{array}$

2 Data and methods $\quad 273$

$3 \quad$ Trends and explanations $\quad 275$

3.1 Cancers strongly linked to infection 278

$\begin{array}{lll}3.1 .1 & \text { Stomach cancer } & 278\end{array}$

$\begin{array}{lll}3.1 .2 & \text { Uterine cancer } & 280\end{array}$

3.1.3 Liver cancer 281

3.2 Cancers not strongly linked to infection 283

$\begin{array}{lll}3.2 .1 & \text { Lung cancer } & 283\end{array}$

$\begin{array}{lll}3.2 .2 & \text { Breast cancer } & 287\end{array}$

4 Discussion 290

5 Acknowlegdements 294

$\begin{array}{ll}\text { Notes } & 295\end{array}$

$\begin{array}{ll}\text { References } & 297\end{array}$ 


\title{
The Cancer Transition in Japan since 1951
}

\author{
Omer Gersten ${ }^{1,2}$ \\ John R. Wilmoth ${ }^{3}$
}

\begin{abstract}
The overall trend of cancer mortality in Japan has been decreasing since the 1960s (agestandardized death rates for ages 30-69), some 20-30 years earlier than in other industrialized countries. Cancer mortality was heavily influenced by Japanese post-war economic recovery, which led to improved living conditions and better control of some common forms of cancer (stomach, cervical) largely caused by infectious agents. However, Japanese wealth and development have also been associated with risky personal behaviors (smoking, drinking) and other conditions, leading to increases in cancers with no known or else very weak links to infection. We call this shift away from infectious and toward non-infectious causes of prevalent forms of cancers the "cancer transition," by analogy to Omran's "epidemiologic transition." The cancer transition described here in the case of Japan must be a part of efforts to revise and update the epidemiologic transition, which should incorporate new knowledge about the role of infection in chronic disease morbidity and mortality.
\end{abstract}

Author for correspondence.

2 Department of Demography, University of California at Berkeley, 2232 Piedmont Avenue, Berkeley, California 94720-2120. Email: omer@demog.berkeley.edu

3 Department of Demography, University of California at Berkeley, 2232 Piedmont Avenue, Berkeley, California 94720-2120. Email: jrw@demog.berkeley.edu 


\section{Introduction}

Due to a remarkable mortality decline after World War II, life expectancy at birth is now higher in Japan than in any other country (PRB 2000). During the last half-century, the Japanese were able to reduce the impact of infectious disease while simultaneously lowering death rates due to degenerative disease among the aged. The latter was accomplished mainly through a marked reduction in cerebrovascular disease, or stroke (Yanagishita and Guralnik 1988). Cancer is now one of the main obstacles to continued improvement in life expectancy. In 1981, cancer overtook stroke as the leading cause of death in Japan and has not since relinquished this top spot (JIN 1999). Indeed, by 1995, the overall death rate for cancer (including all ages and both sexes) was nearly $75 \%$ greater than for the second leading cause of death (JIN 1999).

Since cancer tends to strike at older ages, the absolute cancer burden in Japan is sure to worsen because of its aging population. It is predicted that by 2015 over one in four persons in Japan will be above age 65 (MHW 1951-1996). Like Japan, other industrialized countries will have an increasing percentage of elderly persons in coming years. Furthermore, these nations have also experienced a sharp decline in stroke (Thom 1993), increasing the relative share of cancer mortality. Thus, in Japan and elsewhere, cancer trends are likely to have a major influence on future mortality patterns.

Overall cancer death rates represent an important measure of progress against cancer, with many industrialized countries recently reporting unprecedented declines. In the United States, for instance, observed cancer mortality rates rose for a long period after the collection of national mortality statistics began in the early 1900s. The cancer death rate peaked around 1990, though, and has since continually decreased (Cole and Rodu 1996; Wingo et al. 1999). Similarly, in 15 countries of the European Union, mortality rates for all cancers combined, which had been increasing at least since 1960, peaked in 1988, with a steady and continual decline thereafter (Levi et al. 1997).

Within this background of recent and impressive gains against cancer, this paper investigates where Japan stands as an industrialized country that has seen its life expectancy shoot ahead of all others. Although hundreds of cancers exist, only the few that really drive the overall trend will be highlighted here. In Japanese men these are the cancers of the stomach, liver, lung, and to a lesser degree colorectum and pancreas, while for women this list is augmented by cancers of the uterus and breast. Between 1951 and 1996 these five leading cancers in men and seven in women account for about $80 \%$ of their total sex-specific cancer deaths, although the share of the burden for any of the leading individual cancers changes considerably over this time (MHW 1951-1996).

Omran hypothesized that nations in the second stage of the epidemiologic transition experience a considerable drop from earlier high mortality regimes with life expectancy increasing to 30-50 years. Malnutrition, childhood disease, and severe 
pandemics of infection diminish, but infectious diseases (like tuberculosis and malaria) still remain the leading cause of death. Developing nations move from this "age of receding pandemics" to the third and last "age of degenerative and man-made disease," where mortality is lower overall and deaths are concentrated at older ages. In this last stage, non-communicable and chronic ailments like "heart disease, cancer and stroke replace infection as prime killers" (Omran 1971).

Thus, the classical view is that cancer emerges as an important cause of death in human populations once infections are controlled, during the third stage of the epidemiologic transition. However, the existence of a cancer transition, as illustrated here for Japan, shows that this description is overly simplified, because it overlooks the fact that infection is often an important cause of cancer. Indeed, as a risk factor for this disease, infection may be as important as diet, with perhaps $20 \%$ of all cancers caused by infection (Doll 2001). For specific forms of the disease, Pisani and colleagues (1997) have estimated the fraction of incident cancer cases in 1990 attributable to infection. For three of the cancers highlighted here, this fraction is substantial: $55 \%$ of stomach cancer, $83 \%$ of cervical cancer, and $81 \%$ of liver cancer. Although some data suggest a link between infection and cancers of the lung, breast, colorectum, and pancreas, the observed associations are far weaker (J. Parsonnet, personal communication, September 2001). In this paper, cancers with a strong root in infection will be presented first, followed by those with no known or else very weak links to infection. This general division also forms the basis for an interpretative model of cancer trends in Japan since 1951.

\section{Data and methods}

Detailed annual mortality data for Japan are available beginning in 1951, so we analyzed trends in Japanese cancer mortality from 1951 to 1996. Although the quality of age reporting is generally quite high over this period (M. McConney, personal communication, November 2000; Wilmoth and Lundström 1996), the attribution of cause of death may be more problematic, as discussed below. Age- and cause-specific death rates were derived from published death counts (MHW 1951-1996) and population estimates based on census tabulations and intercensal survival methods (Wilmoth 2002). Unless otherwise stated, all death rates presented here refer to ages 3069 and have been age-standardized using the Japanese population of 1985 as the standard (Tominaga and Oshima 1999) (Note 1). This standard population places more weight on older ages compared to the frequently used Segi-Doll "world standard," based on an estimated world population of the late 1940s and early 1950s (Tominaga 
and Oshima 1999). Although age-adjusted rates are higher when using the 1985 Japanese standard, cancer patterns based on these two standards are quite similar.

A more important choice is the limitation on the age range used in this analysis. A truncated range (ages 30-69) tends to reduce the apparent severity of cancers that typically strike at older ages and, conversely, to increase the importance of cancers that are common during middle adulthood. For example, the age range employed here has the effect of diminishing the relative severity of lung cancer while increasing the role of liver and breast cancers. In spite of this drawback, a focus on ages 30-69 is well justified by known inaccuracies in the attribution of cause of death. In general, deaths attributed to cancer seem to have shifted over time because of changing diagnostic criteria, changing medical practices, and erosion of the social stigma associated with cancer (Davis et al. 1990; Hoel et al. 1993; Jablon et al. 1990).

Although it is impossible to know for sure, it appears that true cancer deaths are now more likely than in the past to be classified as such rather than under some "illdefined" category. Such misattribution seems to affect data quality for the elderly in particular. During 1951-1955, for example, $42 \%$ of Japanese deaths above age 80 were attributed to the ill-defined rubric, "senility without mention of psychosis," whereas only $6 \%$ of deaths in this age range were so classified during 1991-1996. Undoubtedly, many deaths that previously were called "senile" are now assigned to cancer and other causes. A gradual reduction in the under-reporting of cancer deaths could create the appearance of rising cancer mortality rates even if actual trends are stable or declining (Wilmoth 1995).

Unfortunately, there is no definitive solution for problems created by changes in cause-of-death coding. Although there have undoubtedly been shifts in reporting practices affecting cancer data across the age range, such problems are no doubt attenuated if the analysis excludes data for the elderly. Ideally, we would like to include valid data for those over age 70 in Japan because cancer often strikes then. However, concerns about the temporal consistency of cause-of-death coding among the elderly led us to the more prudent strategy of limiting our trend analysis to ages 30-69.

Table 1 shows the 8 cancer groups investigated here (total, stomach, lung, liver, uterus (Note 2), breast, colorectum, and pancreas) and the corresponding codes of the International Classification of Diseases (ICD) for the $6^{\text {th }}$ through $10^{\text {th }}$ revisions (WHO 1992). 
Table 1: ICD codes for cancers included in this analysis, $6^{\text {th }}$ through $10^{\text {th }}$ revisions

\begin{tabular}{llllll}
$\begin{array}{l}\text { Type of cancer } \\
\text { (by site of primary tumor) }\end{array}$ & $\mathbf{6}^{\text {th }} \mathbf{I C D}$ & $\mathbf{7}^{\text {th }} \mathbf{I C D}$ & $\mathbf{8}^{\text {th }}$ ICD & $\mathbf{9}^{\text {th }}$ ICD & \begin{tabular}{l}
$\mathbf{1 0}^{\text {th }}$ ICD \\
\hline All sites
\end{tabular} \\
$\mathbf{1 9 5 1 - 5 7}$ & $\mathbf{1 9 5 8 - 6 7}$ & $\mathbf{1 9 6 8 - 7 8}$ & $\mathbf{1 9 7 9 - 9 4}$ & $\mathbf{1 9 9 5 -}$ \\
Stomach & $140-205$ & $140-205$ & $140-209$ & $140-208$ & C00-C97 \\
Trachea, bronchus, lung & 151 & 151 & 151 & 151 & C16 \\
Liver, gallbladder, bile ducts & 162,163 & 162,163 & 162 & 162 & C33,C34 \\
Uterus & 155,156 & 155,156 & 155,156 & 155,156 & C22-C24 \\
Breast & $171-174$ & $171-174$ & $180-182$ & $179-182$ & C53-C55, C58 \\
Colorectum & 170 & 170 & 174 & 174 & C50 \\
Pancreas & 153,154 & 153,154 & 153,154 & 153,154 & C18-C21 \\
\hline
\end{tabular}

Note: $\quad I C D=$ International Classification of Diseases

Source: WHO 1992

\section{Trends and explanations}

The overall cancer mortality rate in Japan (ages 30-69, age-standardized, both sexes combined) rose during the 1950s but began to decline in the early 1960s (Figure 1). The peak level during the early 1960s contrasts sharply with overall cancer death rates in the United States and the European Union, which peaked some 30 years later. These overall rates are not strictly comparable, because calculations for the United States and European Union countries did not use the same age range and method of standardization (Note 3). Nevertheless, even when all ages and the world population standard are used, the peak in Japan's overall cancer rate still occurs about 20 years earlier than in other developed nations.

For cancers that commonly strike both sexes in Japan, men generally experience twice the death rate of women. Nonetheless, the overall decline in cancer mortality has been driven almost entirely by female trends. Death rates among women have dropped steadily and dramatically since 1961 . Cancer mortality among men, on the other hand, returned to around 1951 levels in the mid-1970s and has stayed relatively stable thereafter (Figure 1). 
Figure 1: Age-adjusted death rates by sex for all cancers combined, Japan, ages 30-69, 1951-1996

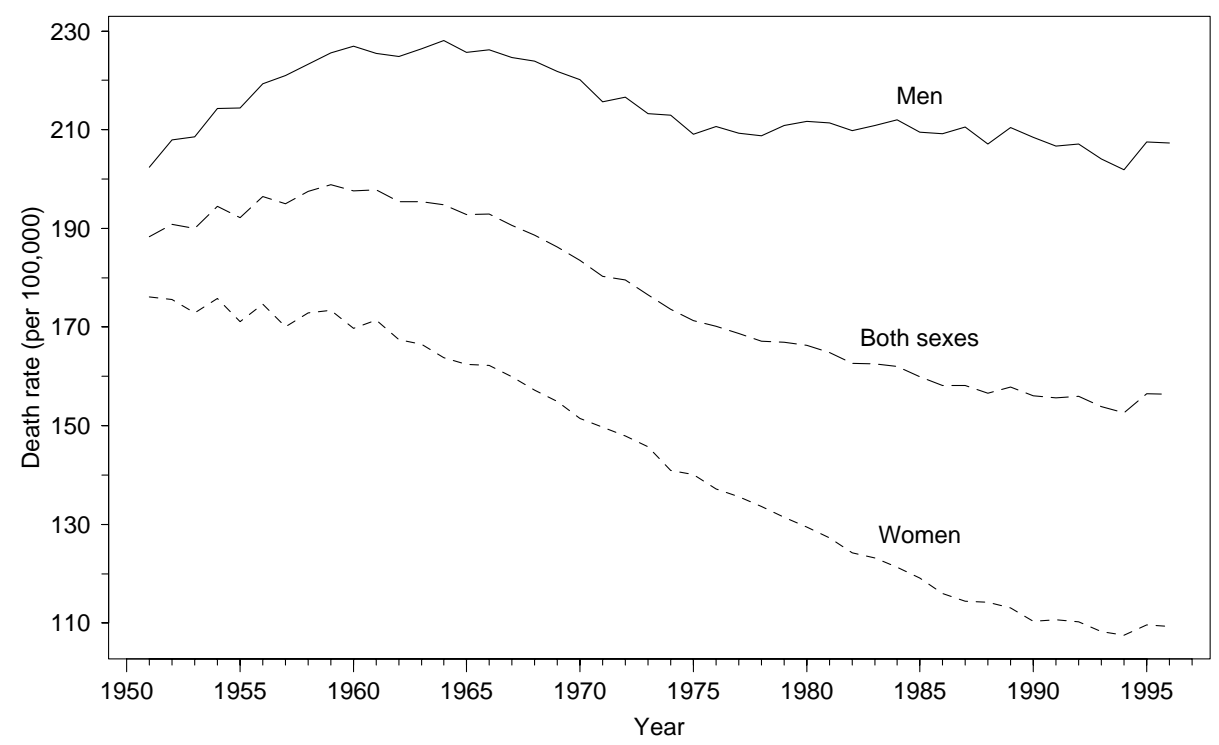

Note: All death rates are age-standardized using the 1985 Japanese total population

Source: $\quad$ MHW 1951-1996; Wilmoth 2002

In 1951, the leading cancers for both Japanese women and men were those linked to infection. For women at that time, stomach, liver, and uterus cancer combined for $71 \%$ of all cancer deaths. By 1996 that figure dropped to 34\% (MHW 1951-1996). Similarly, cancers of the stomach and liver alone accounted for $70 \%$ of all male cancer deaths in 1951, declining to $41 \%$ by 1996 despite liver cancer's rise (MHW 1951-1996). This steeper drop in major cancers affecting women that has not been matched by other increases over this period mainly explains the difference in overall levels by sex. In contrast to the sinking rates of cancers related to infection, $34 \%$ of all female cancer deaths in 1996 were caused by those of the breast, lung, and colorectum. They combined for only $11 \%$ in 1951 (MHW 1951-1996). Likewise, lung, colorectal, and pancreatic cancer in men accounted for 36\% of all cancer deaths in 1996, up from 8\% in 1951 (MHW 1951-1996). Figures 2 and 3 detail the individual cancer patterns for each sex. 
Figure 2: $\quad$ Age-adjusted death rates for seven leading cancers, Japanese women, ages 30-69, 1951-1996

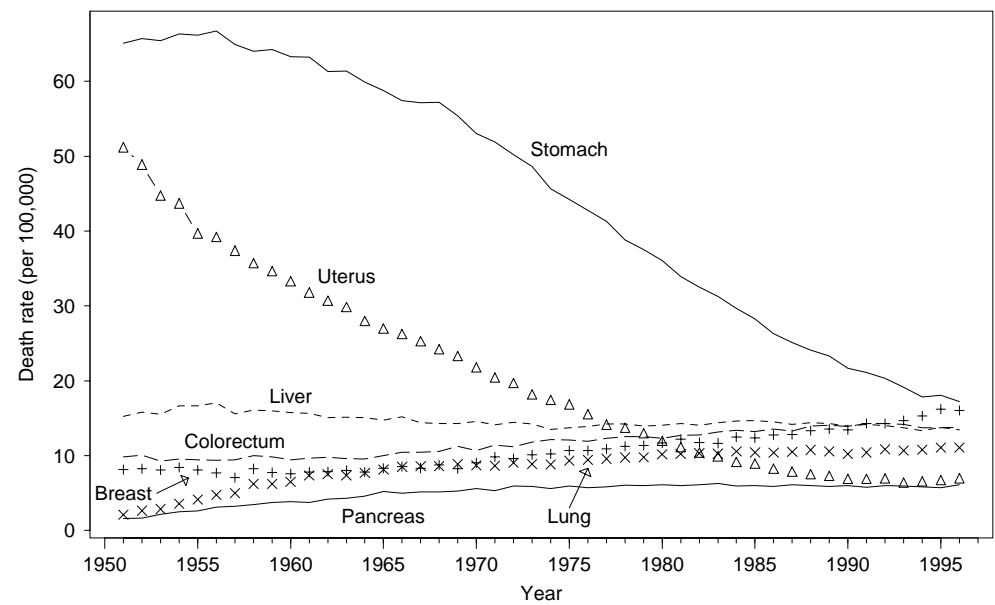

Note: $\quad$ See note for Figure 1

Source: $\quad$ MHW 1951-1996; Wilmoth 2002

Figure 3: $\quad$ Age-adjusted death rates for seven leading cancers, Japanese men, ages 30-69, 1951-1996

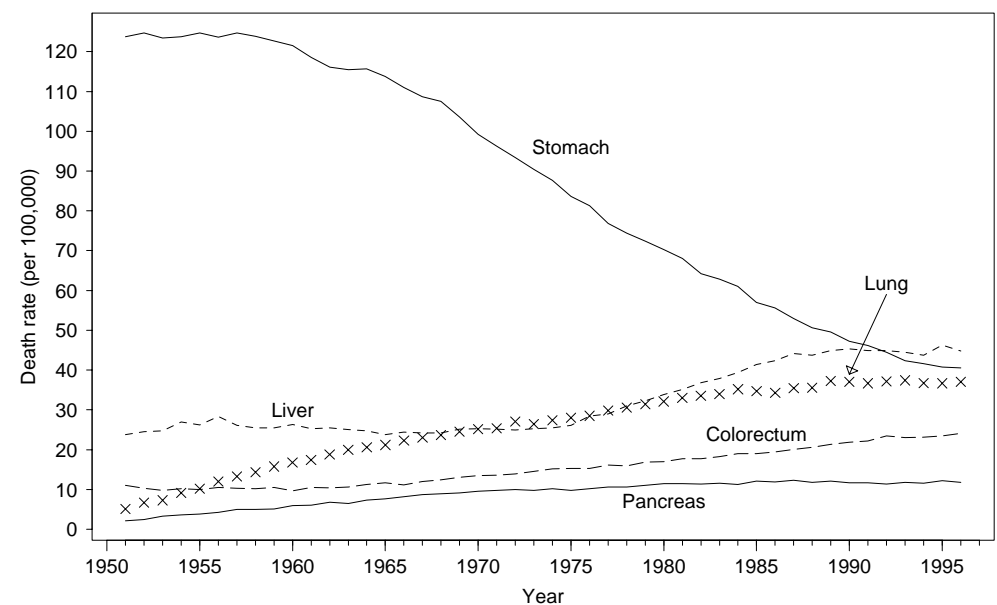

Note: $\quad$ See note for Figure 1

Source: $\quad$ MHW 1951-1996; Wilmoth 2002 


\subsection{Cancers strongly linked to infection}

\subsubsection{Stomach cancer}

Japan has one of the highest rates of stomach cancer mortality in the world and among developed countries ranks first for both men and women (NCI 1999). One measure employed to lower stomach cancer deaths has been regular screenings, in the hope that early detection of the disease and subsequent treatment would improve survival prospects. Stomach cancer screenings began in Japan during the 1960s and the number of people being tested has grown, especially with the 1983 passage of the Health and Medical Services for the Aged Act. The Act ensures screenings for stomach and other cancers for those over age 40. Of all Japanese in this age range, about 14\% (4.3 million) had a stomach cancer screening sometime during 1994 (Inaba et al. 1999). However, despite government support for these screenings and the many people who undergo them, their efficacy is contested (Chamberlain et al. 1986; Fukao et al. 1995; Inaba et al. 1999; Pisani and Parkin 1996). Although the end goal of screening for stomach cancer is mortality reduction, it is not known for sure whether the procedure improves survival prospects significantly or whether it merely detects cancer earlier. It is also possible that screenings prolong life but only for a brief period. If screenings have had an influence on death rates, it seems likely that their impact is outweighed by other factors.

An important reason for the impressive decline in stomach cancer mortality has been a general improvement in the standard of living. Some authors have concluded that the decline represents an "unplanned triumph," considering the lack of success of any specific measures like screenings (Howson et al. 1986). An example of the tie between stomach cancer and the standard of living is the prevalence of the infectious Helicobacter pylori, a gastric bacterium responsible for perhaps $55 \%$ of recent worldwide stomach cancer cases (WHO 1996; Asaka et al. 1997). In Japan H. pylori prevalence has increased in birth cohorts after 1920, highest among those born during World War II and the 1950s when living conditions were compromised. In contrast, the prevalence of the bacterium is lower in cohorts born after the 1950s when Japan started to experience the effects of post-war economic recovery (Replogle et al. 1996; Fujisawa et al. 1999). Coincidental improvements in such areas as sanitation, housing conditions, and food availability after the war likely led to a decline in $\mathrm{H}$. pylori prevalence (Ohno 1985; Replogle et al. 1996; Yoshiike et al. 1996).

Although $H$. pylori is considered a definite cause of stomach cancer (IARC 1994), the bacterium is not sufficient in and of itself to result in disease. Rather, it leads to chronic gastric inflammation and seems to impair the host's defense mechanisms (Asaka et al. 1997). A very small fraction of those infected acquire stomach cancer, 
with the disease developing each year in only about $0.5 \%$ of the 60 million infected Japanese (Uemura et al. 2001). The greatest risk for infection appears to be during childhood and early adult years (Malaty et al. 2002; Malaty 2000; Mendall et al. 1992), with the process of infection and possible resulting cancer resembling a cohort effect (Replogle et al. 1996; Fujisawa et al. 1999). However, more recent events also seem to play a role in levels of the disease, since infection and loss of infection also occur in older adults (Veldhuyzen van Zanten et al. 1994; Kikuchi 2002; Kumagai et al. 1998). Thus, the conditions that led to the lower $H$. pylori prevalence noticeable in birth cohorts of the 1960s and later could also have affected older adults during these periods, lowering their stomach cancer incidence within a relatively short time. The degree to which infection and resulting cancer are linked to cohort factors will partly determine disease rates decades after the 1960s.

Another link between rising living standards and the decline of stomach cancer is the dramatic increase in domestic refrigeration. In 1954, 19.4\% of Japanese households possessed refrigerators or iceboxes, whereas fifteen years later $94.4 \%$ had refrigerators (Replogle et al. 1996). Refrigeration reduces the need for foods such as fish and meat to be cured and preserved in salt or else smoked, both of which are known risk factors for stomach cancer (Coleman et al. 1993; Howson et al. 1986; Muñoz and Franceschi 1997). Salt intake may have thus declined during the growth of refrigeration (Kono et al. 1983; Tanaka et al. 1982). After refrigeration was widespread, salt intake fell from 13.5 (g / person / day) in 1975 to 12.5 in 1990 (Yoshiike et al. 1996). Programs to combat stroke and cardiovascular disease, which began in the 1960s and became more established later, also contributed to less salt consumption. Part of the health education advocated dietary changes, including reduced salt intake (Ohno 1985; Tanaka et al. 1982; Iso 1998).

Refrigeration also helps to retain nutrients in fruits and vegetables (Coleman et al. 1993; Howson et al. 1986; Muñoz and Franceschi 1997), and there is strong evidence that greater consumption of fruits and vegetables lowers the risk of stomach cancer (Kono et al. 1983; Muñoz and Franceschi 1997). Nevertheless, it is uncertain which particular nutrients are most responsible for protection, as they relate to cancer in many and complicated ways (Muñoz and Franceschi 1997; Neugut et al. 1996). Figure 4 shows that Japanese fruit consumption, as recorded by the National Nutrition Survey, rose markedly after 1955, reaching a high point in 1975. Following some decline in consumption since then, fruit intake in 1990 was still about double 1950 levels. On the other hand, the intake of green-yellow and other vegetables shows no long-term trend since 1950. 
Figure 4: $\quad$ Relative trends in intake of fruits, vegetables, and salt, Japan, 1950-1993

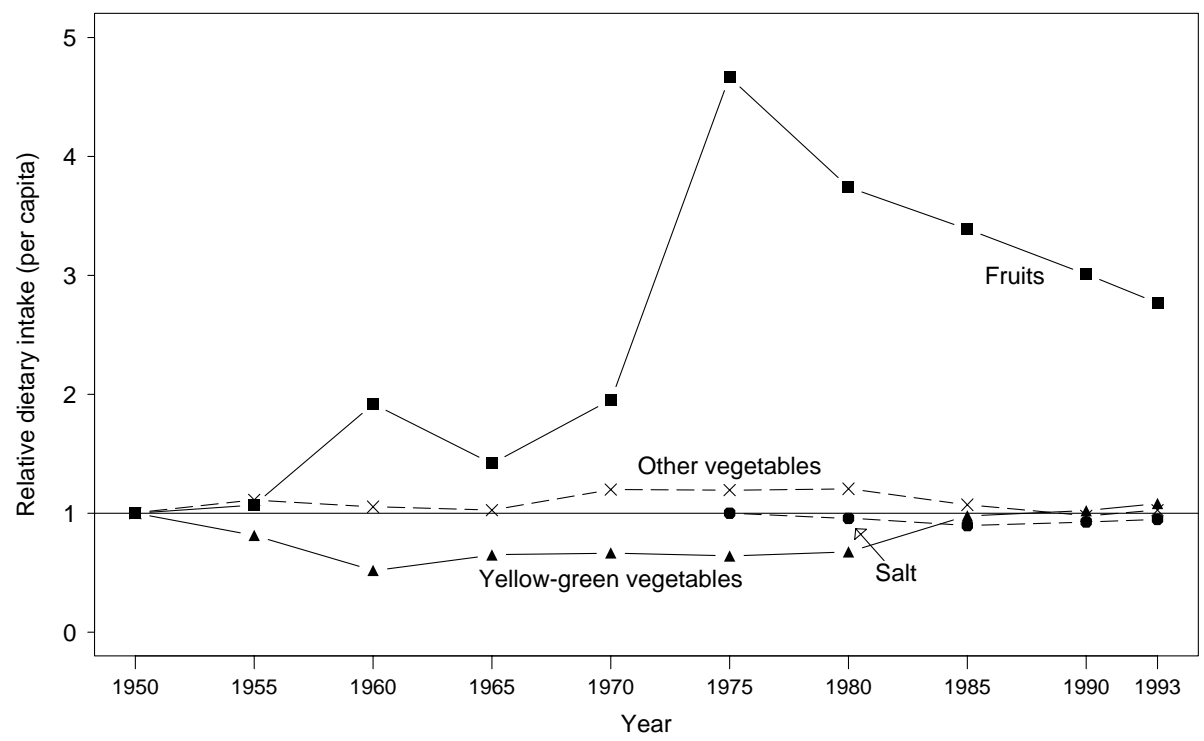

Note: $\quad$ All values are relative to 1950 levels

Source: $\quad$ Annual reports of the National Nutrition Survey of Japan (Yoshiike et al. 1996)

In summary, stomach cancer mortality in Japan seems to have declined due to a combination of factors. Although screenings and early detection may or may not have yielded an increase in survival among those with the disease, dietary changes facilitated by the spread of refrigeration, together with a reduction in the prevalence of $\mathrm{H}$. pylori infection, seems likely to have reduced stomach cancer death rates by means of decreased incidence.

\subsubsection{Uterine cancer}

Of the various uterine sub-sites, the cervix is by far the most commonly struck by cancer and the main cause of cervical cancer worldwide is certain types of the sexually transmitted human papillomavirus, or HPV (Beral et al. 1994; Cannistra and Niloff 1996). Sexual intercourse is therefore a risk factor for cervical cancer and condoms are 
a method of protection. Japanese sexual practices have liberalized since the 1950s, but the use of condoms has also grown markedly (Asayama 1976; Beral et al. 1994; Coleman 1981). The net effect of changing sexual practices on trends in cervical cancer is thus uncertain.

Better established, however, is the role of mass screenings and early detection of the disease on trends in cervical cancer death rates. Since cervical cancer is one of the few cancers with a readily detectable and treatable precursor stage (WHO 1996), organized screening programs can substantially reduce both the incidence of invasive disease and eventual mortality (NIH 1996; IARC 1986). Cuzick et al. (2000) state that "potential reductions in disease of $60-90 \%$ are possible in the three years after screening." The Japanese government has conducted mass screening programs for cervical cancer since 1961 (Sonoda and Yamaguchi 1995) (Note 4). Considering that mass screenings began in that year, it is a mystery that rates began to fall sharply before then (Beral et al. 1994). One hypothesis is that improvements in nutrition, genital hygiene (genital washing and sanitary napkins), and a reduction in frequent, early childbearing play roles in the decline (Beral et al. 1994; Brinton 1992).

Not only has Japanese participation in cervical cancer screenings grown, but also

the ability to detect the cancer at an earlier stage of progression has improved, thus enhancing the chance of survival. Statistics of cervical cancer incidence at four different stages of diagnosis have been collected by the Japan Society of Obstetrics and Gynecology since 1952 (Note 5). A cancer at Stage I is in the earliest phase and is most treatable, a Stage II cancer has progressed further and is less treatable, and so on. Of all Japanese women with cervical cancer recorded by the Society for the period 1953-57, $21 \%$ of cancers were detected at Stage I, 39\% at Stage II, and the remainder at Stages III and IV. In 1991, in contrast, 56\% and 24\% were detected at Stage I and Stage II, respectively (Sonoda and Yamaguchi 1995). Thus, it seems likely that earlier detection of cervical cancer has been a key factor in the reduction of death rates.

\subsubsection{Liver cancer}

Liver cancer is rare in the United States and most west European countries (Tominaga and Oshima 1999) although it is high in Japanese men (Figure 3) (Note 6). The WHO estimates that about $80 \%$ of new liver cancer cases worldwide in 1995 were caused by the hepatitis B and C viruses (HBV and HCV) (WHO 1996). HBV and HCV are also the most important causes of the most common form of liver cancer, hepatocellular carcinoma, or HCC. Over 90\% of liver cancers in Japan are HCC (LCSGJ 1995). Since a common means of transmitting hepatitis is through contaminated blood, it is noteworthy that a survey of Japanese with HCC during 1984-1985 found that 23\% had 
had blood transfusions (LCSGJ 1990). Mansell and Locarnini (1995) estimate that about $30-50 \%$ of current $\mathrm{HCV}$ in Japan was acquired by blood transfusions. Acupuncture appears to be another important route of transmission for HBV and HCV, and studies of spouses (of infected persons) and prostitutes have shown that sexual intercourse can also transmit the viruses (Gust 1996; Mansell and Locarnini 1995). Living with a family member who has one of these viruses raises the chance of infection, and so does intravenous drug use, mainly through the sharing of contaminated needles (Shimotohno 1996). About 5-10\% of infected mothers pass HCV to their newborns (Shimotohno 1996).

Fortunately, an effective vaccine for HBV is available, and Japan's widespread immunization program has lowered HBV prevalence dramatically (Gust 1996; Kane 1998). Indicative of this decline, the number of Japanese with HCC who are also carriers of hepatitis B surface antigen (a HBV marker) went from 40\% in 1970 to 22.5\% in 1987 (LCSGJ 1995). However, unlike HBV there is no effective vaccine for $\mathrm{HCV}$, and HCV's prevalence has not declined (Note 7). Consequently, the proportion of $\mathrm{HCC}$ cases where $\mathrm{HCV}$ is present has increased: about $70 \%$ of individuals with HCC in Japan tested positive for HCV around 1990 (Tanaka et al. 1992).

Although Japan's HCV rate is high and a vaccine for the virus does not exist, progress against transmission has come in the form of blood transfusion screenings. With the discovery of HCV in 1989 (Di Bisceglie 1995), Japan began screenings for the virus the same year (Swinbanks 1989). These screenings have already dramatically reduced blood-transfused hepatitis $\mathrm{C}$, and as a result it is predicted that HCC deaths in 2015 will be reduced to one-third of their 1994 levels (Shimotohno 1996).

In addition to hepatitis infection, excessive alcohol consumption appears to contribute to the onset of HCC. One study suggested that heavy drinking might account for 13\% of HCC cases in the Japanese prefecture of Fukuoka (Tanaka et al. 1992). Although alcohol in and of itself may not cause HCC, it likely contributes to its development when combined with other risks. In one study of those infected with HBV, for example, heavy consumers of alcohol developed HCC about 10 years earlier than moderate drinkers or abstainers (Arii and Tobe 1991). In a study of Japanese with HCC diagnosed and treated between 1980-1981, 32\% had alcohol intake of at least 0.5 liters of sake per day for more than 10 years (LCSGJ 1987).

Japanese men (but not women) have experienced a dramatic rise in liver cancer rates starting in the mid-1970s. Increased alcohol consumption may play a role in this trend. Per capita alcohol consumption in Japan rose fourfold from 1950 to the early 1980s (Makimoto and Higuchi 1999). Male drinking habits almost entirely propelled this increase. Data from 1984 indicate that $40 \%$ of Japanese men over 18 years old were heavy drinkers (over $30 \mathrm{ml}$ alcohol/day), whereas only $3 \%$ of Japanese women were so classified. The greater availability of alcoholic beverages after World War II and the 
economic growth that made them more affordable seem to have contributed to this rise in male drinking (Parrish et al. 1991). Also, smoking may have an independent influence on increasing liver cancer risk (Arii and Tobe 1991; Stuver and Trichopoulos 1994; Tanaka et al. 1992), and thus the disproportionate rate of Japanese male smoking (discussed in the lung cancer section) could contribute to liver cancer's onset.

The rise in liver cancer death rates among Japanese men during the 1970s may also be linked to patterns of illegal drug use in the years following World War II. The intravenous use of methamphetamines was very common in Japan at this time. The number of methamphetamine-related arrests peaked in 1954 and subsided a few years later. The drug's popularity during this period has been attributed to depressed economic and psychological conditions in the war's aftermath (Greberman and Wada 1994; Wada 1994). Men in Japan were about nine times more likely than women to have used the drug during this period (Greberman and Wada 1994), and since methamphetamine use appears greatest in the early post-war period, these phenomena might help explain increased liver cancer death rates during the 1970s (Easton 1999). Because liver cancer takes 15-60 years to develop after hepatitis infection (Mansell and Locarnini 1995), a link between the rise of methamphetamine use in the early post-war period and increased liver cancer death rates among Japanese men during the 1970s is certainly plausible (Easton 1999).

In summary, liver cancer is unusually common in Japan compared to other highly developed countries and has increased dramatically among men (but not women) in recent decades. Infection with the hepatitis B or C viruses is known to be a primary cause of the disease, which is also aggravated by alcohol consumption. Hepatitis infection in Japan has been linked to contaminated blood, acupuncture, sexual intercourse, and intravenous drug use. Despite a secular increase in alcohol consumption among men, it seems likely that liver cancer death rates will drop in the future as hepatitis is controlled by means of vaccination, blood screening, and other preventive measures.

\subsection{Cancers not strongly linked to infection}

\subsubsection{Lung cancer}

Lung cancer death rates are influenced mainly by patterns of tobacco consumption, most commonly in the form of cigarette smoking (Note 8). One study concluded that $67 \%$ of lung cancer cases in Japan were caused by smoking (Sobue et al. 1991). As in other countries, lung cancer in Japan bears the imprint of past smoking trends. A shortage of cigarettes during WWII left many Japanese smokers unable to continue 
their habit for a period of perhaps 5-10 years (Figure 5; Hirayama 1987; Mizuno et al. 1989). A cessation of this duration is often sufficient to cause a substantial reduction in the risk of developing lung cancer, especially for persons who have been smoking for less than about 20 years (Sobue et al. 1991). Since relatively few Japanese smoked before the war, and since most were forced to discontinue the habit for several years at the end of the war, Japan's near-zero lung cancer death rates in 1951 are not surprising. Furthermore, the steady rise in tobacco consumption after 1945 (Figure 5) coincides with a new epidemic of lung cancer starting in the 1950s and reaching full force some 30 years later (Figure 3).

Figure 5: Daily adult tobacco consumption, United States (1920-1985) and Japan (1920-1984)

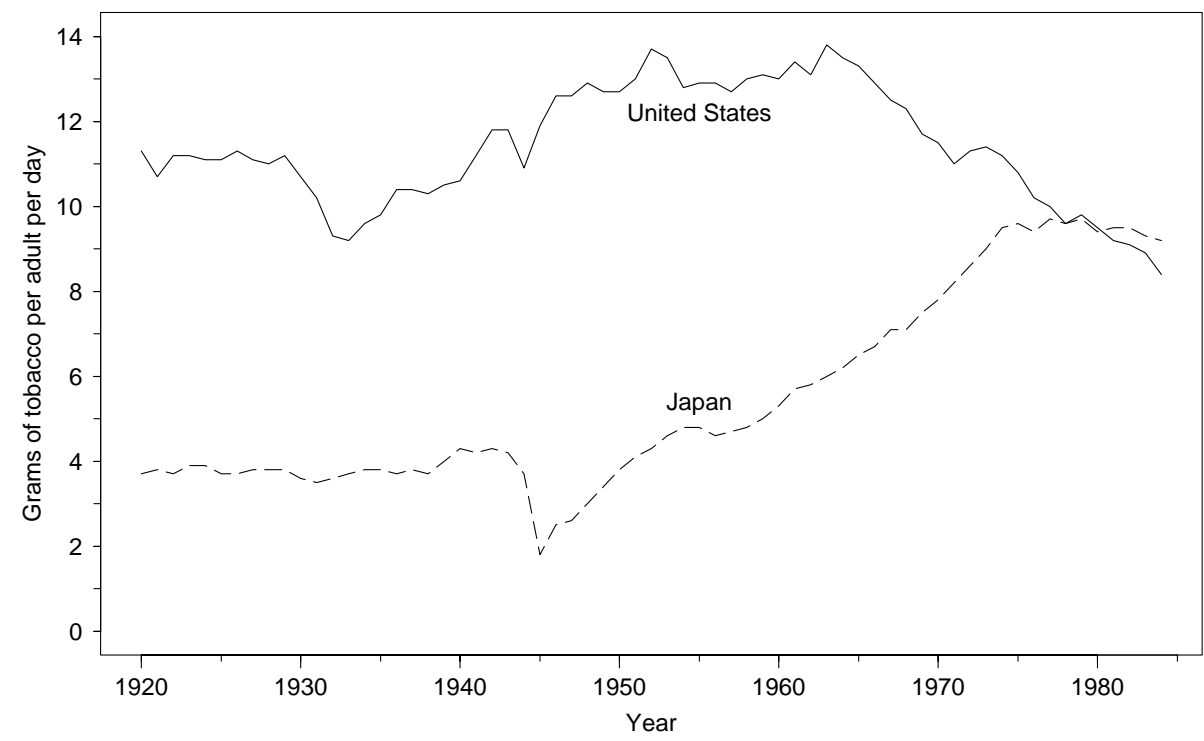

Source: Nicolaides-Bouman et al. 1993 
The rise in lung cancer death rates for Japanese men slowed down around the mid1980s. This trend may be explained by at least three factors. First, as shown in Figure 5, tobacco consumption reached a plateau about 10 years prior. Second, the amount of tar in tobacco began declining from the 1960s in Japan, and lower tar content appears to diminish the risk of lung cancer (Hanai et al. 1988; Hirayama 1987). The introduction of filter cigarettes and changes in the type of tobacco helped to reduce tar levels from 23.7 (mg per cigarette) in 1967 to 14.2 in 1985 (Hirayama 1987). Third, the deceleration in the male lung cancer mortality trend may also indicate that the epidemic had reached a saturation point, with even the oldest cohorts (among those analyzed here) having smoked continuously for most of their adult lives (Hirayama 1987).

For a deeper understanding of lung cancer patterns, we should examine various aspects of smoking trends. For example, one might expect that the rise in tobacco consumption corresponds to a rise in the prevalence of smoking (proportion of smokers among adults). However, trends in smoking prevalence over time appear inconsistent with the rise of lung cancer in Japan. The prevalence of smoking among Japanese women over age 15 remained fixed at around 15\% from 1958 onward, while for men in this age range prevalence actually declined over the same time period. About $70 \%$ of men were smokers in 1958, but this figure fell to around 50\% in 1997 (Figure 6). However, although smoking prevalence remained constant or even declined since the late 1950s, smoking intensity (number of cigarettes per smoker per day) rose markedly. Male smokers, for instance, averaged 24 cigarettes per day in 1997, double the amount they had smoked in 1958 (Figure 7). Thus, while relatively fewer people are now smoking in Japan, they are smoking more cigarettes than they used to. 
Figure 6: Cigarette smoking prevalence by sex, Japan, age 15 and above, 1958-1997

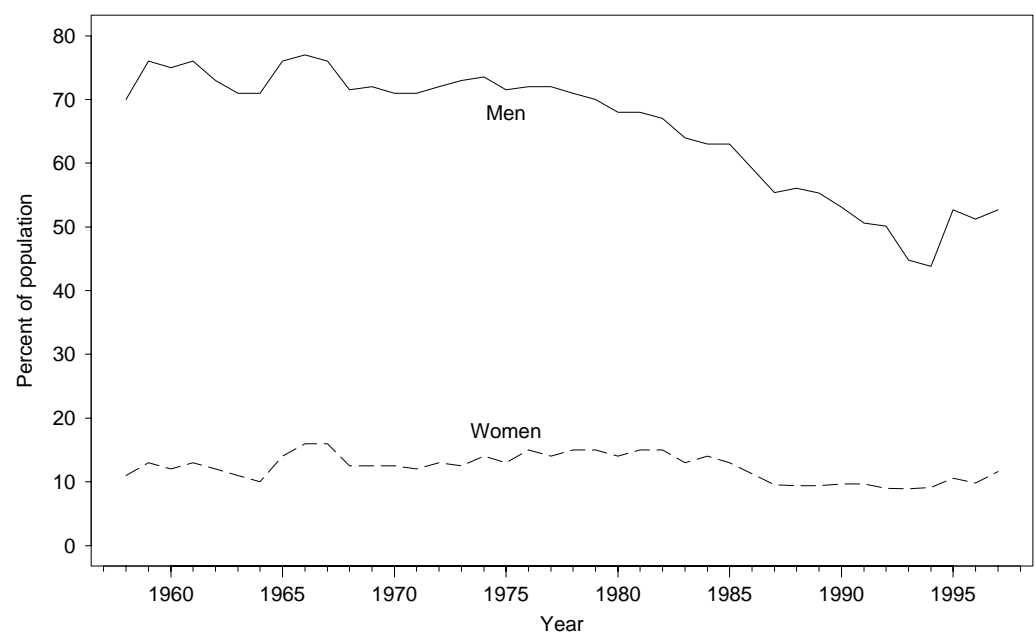

Source: $\quad$ MHW 1989; MHW 1990; MHW 1998; Nicolaides-Bouman et al. 1993

Figure 7: $\quad$ Cigarette smoking intensity by sex, Japan, age 15 and above, 1958-1990

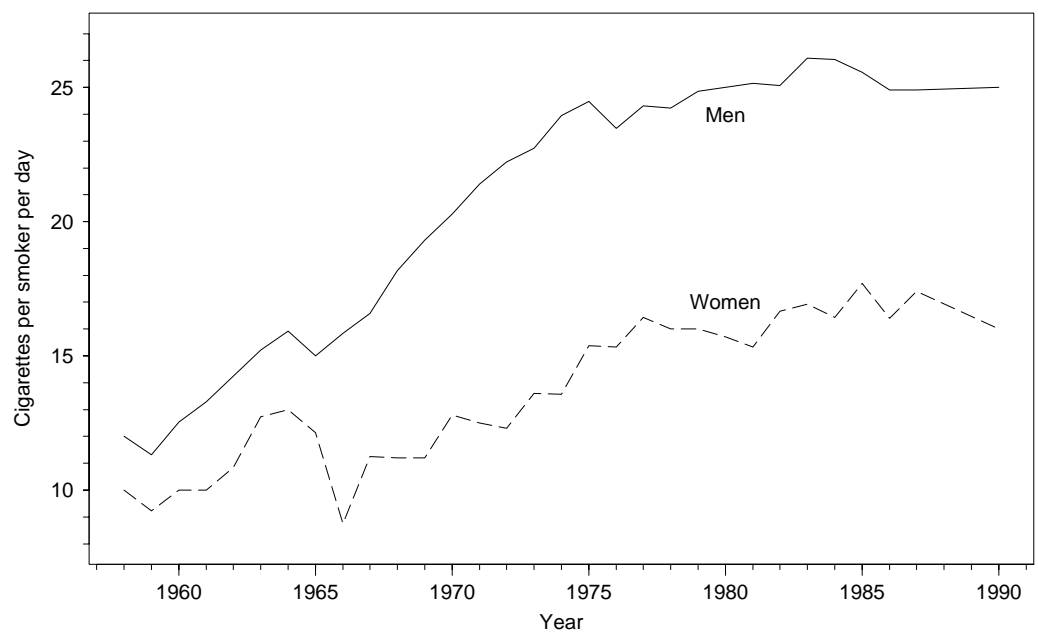

Source: Hatano 1989; Nicolaides-Bouman et al. 1993; WHO 1997b 


\subsubsection{Breast cancer}

Although it is still increasing, Japan's breast cancer death rate was among the lowest of any developed nation (NCI 1999). In developed countries with a high incidence of breast cancer, screenings of the disease using mammography have become commonplace. These screenings have proven very effective in reducing case mortality for women aged 50 years and over (Coleman et al. 1993; Ohuchi et al. 1993). Currently in Japan, however, detection for breast cancer is made almost entirely through physical examination alone, a method considered inferior to mammography for discovering early stage breast cancer (Kuroishi et al. 1991; Morimoto et al. 1997; Ohuchi et al. 1993). A select number of Japanese prefectures began screenings with mammography in the early 1990s (Ohuchi et al. 1993), but such screenings could only slightly affect the last few years of the trends examined here.

The many risk factors for breast cancer cannot be ranked in terms of importance since they are interrelated and their mechanisms of action are not fully understood. For example, breast cancer seems partly caused by patterns of exposure to estrogens, but the precise hormonal interactions have been difficult to pinpoint (Coleman et al. 1993). Some of the factors thought to increase the risk of breast cancer are as follows: 1) earlier age of menarche, 2) lower completed parity, 3) later age of first childbirth, 4) increased height/weight, 5) increased nulliparity or childlessness, 6) later age of menopause, and 7) an increasingly "westernized" diet (Coleman et al. 1993; Minami et al. 1996; Tominaga and Kuroishi 1995; Tung et al. 1999; Wakai et al. 1995).

Factors one through four are represented historically for Japan in Table 2. The mean age at menarche has declined gradually since the 1920s, with some change of trend during and after World War II. This decline has continued in recent decades, although at a slower pace (Hoshi and Kouchi 1981; Moriyama et al. 1977). Of course, the mean age at first childbirth has moved in the opposite direction, rising from around 24 in 1950 to around 27 in 1995. Not only is first childbirth occurring later, but also women are having fewer children. The total fertility rate (TFR) dropped precipitously, from 3.65 in 1950 to 2.14 in 1965 , but decreased more slowly since then, reaching 1.42 in 1995. Nulliparity, or childlessness, has actually declined over this period (Hoel et al. 1983; Inoue et al. 1994). Average height and weight have increased over time for Japanese women aged 60-69, and this pattern is the same for nearly all age groups, the lone exception being stable weight for young women (Hatano 1989). Some studies have reported a gradual increase in the average age of menopause in Japan (Hoel et al. 1983; Kono et al. 1990) (Note 9). Finally, as described below, the Japanese diet has become more "westernized." Thus, all major risk factors for breast cancer have worsened over time in Japan, with the exception of the decrease in childlessness. 
Table 2: $\quad$ Trends in selected risk factors for breast cancer, Japan, 1950-1995

\begin{tabular}{|c|c|c|c|c|c|c|c|c|c|c|}
\hline Risk factors & 1950 & 1955 & 1960 & 1965 & 1970 & 1975 & 1980 & 1985 & 1990 & 1995 \\
\hline \multicolumn{11}{|l|}{ Reproductive } \\
\hline Mean age at menarche ${ }^{1}$ & 15.1 & 14.2 & 13.6 & 13.2 & 12.9 & 12.7 & 12.5 & - & - & - \\
\hline Mean age at first birth ${ }^{2}$ & 24.4 & 24.8 & 25.4 & 25.7 & 25.6 & 25.7 & 26.4 & 26.7 & 27.0 & 27.5 \\
\hline Total fertility rate ${ }^{2}$ & 3.7 & 2.4 & 2.0 & 2.1 & 2.1 & 1.9 & 1.8 & 1.8 & 1.5 & 1.4 \\
\hline \multicolumn{11}{|l|}{ Height / Weight (ages $60-69$ ) } \\
\hline Female height $(\mathrm{cm})^{3}$ & 143.8 & - & 144.3 & - & - & 146.1 & - & 147.8 & - & - \\
\hline Female weight $(\mathbf{k g})^{3}$ & 44.5 & - & 46.0 & - & - & 48.9 & - & 51.3 & - & - \\
\hline
\end{tabular}

Note: $\quad$ Ages at menarche were estimated based on a regression equation fitted to Japanese data for years 1950-1980

Source: $\quad$ (1) Hoshi and Kouchi 1981; (2) MHW 1951-1996; (3) Hatano 1989

The main features of Japan's diet are illustrated in Figure 8, which shows the relative change in selected nutritional intake from 1950 to 1990. An important trend is the rise in consumption of animal products such as meat and eggs. For instance, in 1990 meat and egg consumption rose about 7 and 6 times, respectively, when compared to 1950 levels. As a result of these and other changes, fat intake has risen considerably, although it has leveled off since 1975. At the same time, carbohydrate intake has gone down. As this graph shows, rice consumption, the main provider of carbohydrates, decreased by almost $40 \%$ during this period. Thus, total energy consumption has essentially stayed level, while the percentage of fat in the diet, especially animal fat, has gone up. Only about $8 \%$ of calories came from fat in 1950 , whereas about $25 \%$ did so in 1985 (Weisburger 1997). 
Figure 8: $\quad$ Relative trends in intake of major dietary components, Japan, 1950-1993

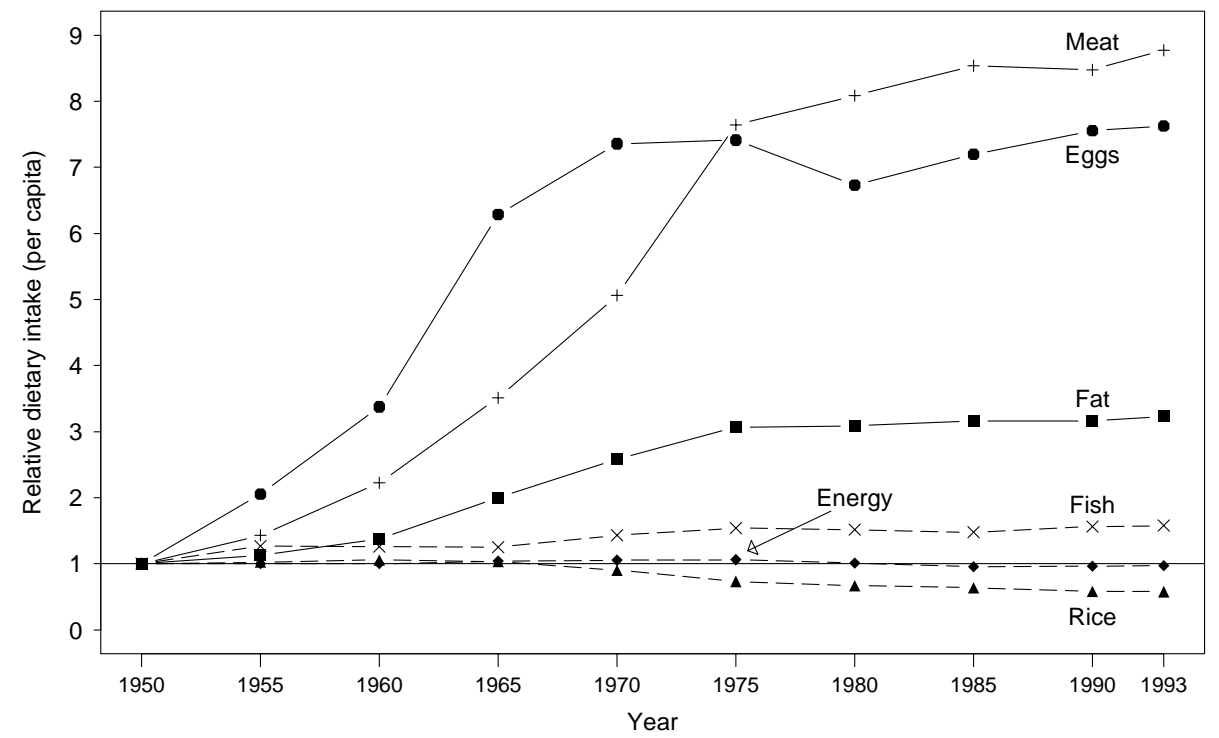

Note: $\quad$ All values are relative to 1950 levels

Source: Annual reports of the National Nutrition Survey of Japan (Yoshiike et al. 1996)

Compared to Japan's traditional diet, a "westernized" diet may be defined roughly as having some of the following characteristics: lower intake of carbohydrates and greater intake of fruits, animal products, and fats, especially saturated fat of animal origin. Using this definition, Japan's diet has clearly become more westernized. This dietary transition helps explain the rising trends in height and weight, and the earlier age of menarche already described (Note 10). Through these mechanisms and perhaps through more direct effects as well, the westernization of diet has likely contributed to the rise of breast cancer mortality in Japan (Hirose et al. 1999; Ishimoto et al. 1994; Tominaga and Kuroishi 1995) (Note 11). 


\section{Discussion}

Two major trends provide the context for a discussion of the cancer transition occurring in Japan since 1951. First, due to enormous reductions in stroke and other major diseases, cancer has become an increasingly important cause of death. Nevertheless, the overall risk of cancer mortality at a given age is declining. Unprecedented declines in overall cancer death rates during the late 1980s and 1990s were reported in the United States, Canada, and countries of the European Union (Cole and Rodu 1996; Levi et al. 1997; Wingo et al. 1999). While Japan also experienced an overall cancer mortality decline, it began much earlier, during the 1960s or 1970s (depending on the method of age-standardization and age ranges employed). A key result of this analysis, then, is that the cancer decline affecting other industrialized countries during the last decade is, in fact, around 20-30 years old in the case of Japan.

The overall decline of cancer mortality, in Japan and elsewhere, must be understood in light of trends in specific forms of the disease. The various etiologies that underlie different types of cancer have led to shifts in their share of the mortality burden over time. The overall decline was driven by female trends, as cancer mortality among Japanese men has been relatively stable since the mid-1970s. For men, a large decline in stomach cancer has been countered by increases in lung and liver cancer. Cancer death rates for Japanese women, on the other hand, have dropped consistently since around 1960, driven by precipitous declines in stomach and uterine cancer, without the large increases in lung and liver cancer experienced by men.

Although we have emphasized the temporal aspect of this study, it is also worth noting that cancer patterns in Japan are often extreme relative to other industrialized nations: 1) stomach cancer rates are among the highest in the world; 2) lung cancer levels are relatively low, yet the increase among men is one of the most rapid among industrialized nations; 3) liver cancer, which is rare in most developed countries, is now the most deadly form of the disease among Japanese men; 4) breast cancer among Japanese women, though increasing, has one of the lowest levels of any developed country.

One might wonder if the legacy of atomic bomb radiation in Japan during World War II helps to account for these differences. Our review of the available evidence suggests that its impact on cancer mortality rates has been minimal (Note 12). Nevertheless, cancer trends in Japan are clearly the product of a social and economic history that was heavily influenced by World War II and the process of post-war reconstruction. Poor living conditions during and after the war led to a higher prevalence of $H$. pylori infection, a major cause of stomach cancer, among cohorts born in the 1940s and the 1950s relative to those before and after. Intravenous drug use, a risk factor for liver cancer because it is a source of hepatitis infection, was more 
prevalent during the early post-war period as well. Whereas these aspects of Japan's war experience led to increased cancer risks, cigarettes were in short supply during and immediately after the war, which led to a (temporary) cessation of smoking among older smokers and a delayed start for new smokers. Thus, the privation and disruption of war probably raised the risks of stomach and liver cancer, but lowered the risks of lung and pancreatic cancer, which are both linked to cigarette smoking.

Post-war economic recovery has also had its effects on cancer trends in Japan. As alcohol became more affordable, excess alcohol consumption, a risk factor for liver cancer, became more prevalent. Likewise, cigarette smoking became more affordable and widespread after World War II, creating a new epidemic of lung cancer that emerged slowly over a period of several decades. Finally, westernization of the Japanese diet may have contributed to a rise in breast cancer.

Since cancer etiology is often linked to poverty or wealth, certain changes in cancer patterns tend to occur during the course of economic development. Among women, uterine cancer tends to become less common as screening and treatment are deployed more effectively (Brinton 1992; Beral et al. 1994), whereas breast cancer increases due to a complex set of factors usually associated with social and economic development (later and lower fertility, dietary change, etc.) (Coleman et al. 1993; Minami et al. 1996; Tominaga and Kuroishi 1995; Tung et al. 1999; Wakai et al. 1995). For both men and women, stomach cancer tends to decline thanks to better methods of preserving foods and controlling $\mathrm{H}$. pylori infection (Howson et al. 1986; Replogle et al. 1996), whereas lung and sometimes liver cancer tend to increase due to excessive smoking and drinking habits, which are facilitated by economic development (Parrish et al. 1991; WHO 1997b; Jernigan et al. 2000). Rises in pancreatic cancer also seem most tied to smoking (Howe 1994; Lin et al. 1998; Parkin et al. 1994; Tominaga and Kuroishi 1998) and although colorectal cancer's etiology is not well understood it is positively correlated with development (Levin 1992; Coleman et al. 1993; Kono 1996; Potter 1996; Wilmink 1997).

To conceptualize the cancer transition that occurs as nations develop, we apply elements of Omran's theory of the epidemiologic transition (Omran 1971). During the third and last stage of this transition, cancer should become more prominent as acute infectious diseases decline and are replaced by the chronic degenerative ailments of old age. Indeed, the Japanese example illustrates how the relative impact of cancer has grown during recent decades. However, some forms of cancer mortality have in fact decreased over this period, whereas other cancers have become more common. In general, it is those cancers that have been linked to infection that are decreasing (stomach, cervical) or that seem likely to decrease in the future (liver). On the other hand, cancers linked to personal behaviors such as smoking (lung, pancreatic) or to modern fertility patterns (breast), and for which no major infectious agent has yet been 
identified, are now increasing and may continue to do so. Thus, a significant feature of the epidemiologic transition takes place not only between broad categories of causes of death, but also within the group of all cancers. Figure 9 summarizes this relationship schematically.

Figure 9: Comparison of the epidemiologic and cancer transitions

\section{Major causes of death}

\begin{tabular}{|l|l|l|}
\hline \multicolumn{1}{|l}{ Before - Infectious disease } & \multicolumn{1}{l|}{ After - Non-infectious disease } \\
\hline Epidemiologic transition & $\begin{array}{l}\text { Malaria } \\
\text { Tuberculosis } \\
\text { Smallpox }\end{array}$ & $\begin{array}{l}\text { Cancer } \\
\text { Heart disease } \\
\text { Stroke }\end{array}$ \\
\hline Cancer transition & $\begin{array}{l}\text { Stomach }(H . \text { pylori) } \\
\text { Cervix }\left(\mathrm{HPV}^{1}\right) \\
\text { Liver }\left(\mathrm{HBV}^{\prime} \text { and } \mathrm{HCV}^{2}\right)\end{array}$ & $\begin{array}{l}\text { Lung, pancreas (smoking) } \\
\text { Colorectum (development) } \\
\text { Breast (diet and fertility) }\end{array}$ \\
\hline
\end{tabular}

Note: $\quad{ }^{1}$ Human papillomavirus (HPV)

${ }^{2}$ Hepatitis B virus (HBV) and hepatitis C virus (HCV)

Although we have concentrated on the case of Japan, the notion of a cancer transition is applicable to other developed countries as well. The United States, Canada, and European nations have experienced similar historical cancer patterns as described here (Becker 1998; McLaughlin et al. 1997; NCI 1999; Murray and Lopez 1996). For instance, between 1955 and 1994 for women in European Union countries, stomach and uterine cancer dropped by at least half as lung cancer doubled and breast cancer rose (Levi et al. 1999). Some authors have considered cancer along with other diseases in many of these countries in postulating a new "fourth stage" of epidemiologic transition. Olshansky and Ault (1986), for example, argue that we have entered an "age of delayed degenerative diseases." This new stage should be characterized by improvements in survival at advanced ages for diseases common in the third stage, not by any fundamental change in the composition of major killers. Elsewhere, Olshansky and colleagues attribute the survival gains during this fourth stage of epidemiologic transition to medical advances that have "manufactured" additional years of life (Olshansky and Carnes 2001). 
Rogers and Hackenberg (1987) offer another vision for how the theory of the epidemiologic transition should be amended, claiming that Omran's framework does not aid an understanding of recent trends. In particular, they contend that Omran's theory cannot adequately account for declines in stroke, ischaemic heart disease, and various types of cancer. In their view, the theoretical basis needed to understand recent trends in chronic and degenerative diseases comes from realizing the important role of destructive personal behaviors and social pathology. Furthermore, they argue that, "because the theory's last stage does not account for the possible total eradication of infectious diseases, some age groups or specific subpopulations may have progressed past the last stage in the epidemiologic transition theory" (p. 235).

In conclusion, these earlier attempts to amend or to modify Omran's depiction of the epidemiologic transition are useful, but they miss an important point that we emphasize here. In short, it seems clear that the decline of infectious disease that lies at the heart of the classical theory has a much broader significance than was known at the time it was proposed. We have emphasized the connection between infection and cancer, but others have documented the role of infectious agents in a broad range of chronic and degenerative diseases (Lorber 1996; Costa 2000; Olshansky et al. 1997; Zimmer 2001). Rather than pointing toward a new stage of epidemiologic transition, these observations suggest that industrialized countries may still be completing Omran's original transition. This interpretation makes sense if the transition's defining elements are a substantial reduction of disease and death due to infectious sources, and a rise of age-related degenerative conditions due to biological aging, environmental factors other than infection, and personal behaviors. For a more complete theory of the epidemiologic transition, we need a theory that recognizes the continuity of the battle against infection, while also taking account of changing environmental exposures, personal habits, and medical practices. 


\section{Acknowledgements}

This research was supported by grants R01-AG11552 and P30-AG12839 from the National Institute on Aging. We are grateful to Shiro Horiuchi for comments on an earlier version of the paper. Some of the cause-of-death mortality data analyzed here were supplied by Shigesato Takahashi at the National Institute of Population and Social Security Research in Tokyo, Japan. Long Wang and Lijing Yan also helped in assembling the raw data. The resources provided by the Max Planck Institute of Demographic Research in Rostock, Germany, also made this paper possible. 


\section{Notes}

1. The standardization method used in this analysis is well known and can be found, for example, in Parkin et al. (1992).

2. While it might be helpful to present only data for cervical cancer (the other main component of uterine cancer being endometrial), there is reason to keep the group aggregated. It is sometimes difficult to distinguish in which part of the uterus a cancer arose, leading to misdiagnosis. Further, unspecified uterine cancers may disproportionately really be those of the cervix (Beral et al. 1994). Given the aggregation, cervical cancer is nevertheless the dominant sub-site, accounting for about $70-95 \%$ of the total depending on whether one examines more recent or earlier years (Sato et al. 1998; Sonoda and Yamaguchi 1995).

3. Cole and Rodu (1996) analyze trends in age-adjusted cancer mortality over the full age range, standardized using the United States age distribution of 1940. Wingo et al. (1999) also present overall age-adjusted rates but use the 1970 United States population as their standard. Levi et al. (1997) use age- and sex-standardized mortality rates based on the world standard (Parkin et al. 1997).

4. The Miyagi Prefecture provides an example of the growth of screenings for cervical cancer that has occurred throughout Japan. In 1965, of all women over age 30 in Miyagi, 5.4\% underwent a screening in that year. This participation rate rose to nearly 30\% in 1994 (Sato et al. 1998).

5. It is estimated that the Society records cervical cancer information covering about $40 \%$ of the Japanese population.

6. Detection of liver cancer seems to have improved since 1970, so rates before then may be underreported (Makimoto and Higuchi 1999; Stuver and Trichopoulos 1994).

7. The absolute number of Japanese infected with HCV has almost certainly seen a real increase, although historic data on HCV prevalence seems to be unavailable (Arii and Tobe 1991). A recent estimate suggests that about $2.3 \%$ of the Japanese population is now infected by HCV (WHO 1997a). This rate is high among industrialized nations, where less than $1 \%$ of the population is infected in almost all cases (WHO 1997a).

8. Some controversy surrounds the contribution of diet to lung cancer (Gao et al. 1993; Koo 1997; Wynder et al. 1992). 
9. A study of women in Hiroshima and Nagasaki found that the mean age of menopause was 48.8 for women born during 1880-1899 but 49.9 for those born during 1910-1914 (Hoel et al. 1983).

10. A limited food supply during and shortly after World War II seriously disturbed child growth, delaying the age at menarche and leading to shorter heights and lesser weights. The availability of foods after this time helped lower the age of menarche and a westernized diet contributed to height and weight gains.

11. Although westernization of the Japanese diet may have contributed to an increase in breast cancer, its unfavorable impact on health and mortality should not be exaggerated. First, it should be noted that the Japanese diet is still far from resembling that of many western countries. For example, whereas Japan's fat intake was about $25 \%$ of total calories in 1985, the American diet in the same year had about $44 \%$ of total calories from fat (Weisburger 1997). Second, the "traditional" diet consumed for about ten years after World War II was deficient in animal protein and essential micronutrients. The increased consumption of fruits, meats, and other animal products beginning in the late 1950s has improved resistance to infectious disease (Kobayashi 1992; Ohno 1985). Notably, one of the diseases for which a westernized diet may improve resistance is $\mathrm{H}$. pylori, a cause of stomach cancer. It may be, however, that at some point Japanese women started eating foods that more than compensated for earlier nutritional deficiencies and that contributed to a rise in breast cancer.

12. Of the cancers highlighted here, A-bomb survivors (those exposed to radiation) have been found to have elevated risks of stomach, lung, and breast cancer. However, previous radiation exposure does not seem to increase the risk of acquiring uterine, liver, colorectal, and pancreatic cancer (Kato 1986; Nakatsuka and Ezaki 1986; Pierce et al. 1996). When taking into account the millions of Japanese not exposed to radiation, as well those with exposure, the attributable risk is quite small (Pierce et al. 1996; Radiation effects research foundation, personal communication, February 2000). 


\section{References}

Arii S, Tobe T. (1991). Epidemiology in Japan and the world. In: Okuda K, Tobe T, Kitagawa T, editors. Early detection and treatment of liver cancer. Gann monograph on cancer research no. 38. Tokyo: Japan Scientific Societies Press: $17-26$.

Asaka M, Takeda H, Sugiyama T, Kato M. (1997). "What role does Helicobacter pylori play in gastric cancer?" Gastroenterology, 113:S56-60.

Asayama S. (1976). "Sexual behavior in Japanese students: comparisons for 1974, 1960, and 1952." Arch Sex Behav, 5:371-90.

Becker N. (1998). "Cancer mortality and prevention in the European Union." Eur J Surg Oncol, 24:370-4.

Beral V, Hermon C, Muñoz N, Devesa SS. (1994). Cervical cancer. In: Cancer incidence and mortality. Cancer surveys no. 19-20. Oxford: Oxford University Press: $265-85$.

Brinton LA. (1992). Epidemiology of cervical cancer-overview. In: Muñoz N, Bosch FX, Shah KV, Meheus A, editors. The epidemiology of cervical cancer and human papillomavirus. International agency for research on cancer (IARC) scientific publications no. 119. Lyon: IARC: 3-23.

Cannistra SA, Niloff JM. (1996). "Cancer of the uterine cervix." $N$ Engl J Med, 334:1030-8.

Chamberlain J, Day NE, Hakama M, Miller AB, Prorok PC. (1986). "UICC workshop of the project on evaluation of screening programmes for gastrointestinal cancer." Int J Cancer, 37:329-34.

Cole P, Rodu B. (1996). "Declining cancer mortality in the United States." Cancer, 78:2045-8.

Coleman MP, Estève J, Damiecki P, Arslan A, Renard H. (1993). Trends in cancer incidence and mortality. International agency for research on cancer (IARC) scientific publications no. 121. Lyon: IARC.

Coleman S. (1981). "The cultural context of condom use in Japan." Stud Fam Plann, 12:28-39.

Costa DL. (2000). "Understanding the twentieth-century decline in chronic conditions among older men." Demography, 37:53-72. 
Cuzick J, Sasieni P, Davies P, Adams J, Normand C, Frater A, van Ballegooijen M, van den Akker-van Marle E. (2000). "A systematic review of the role of human papilloma virus (HPV) testing within a cervical screening programme: summary and conclusions." Br J Cancer, 83:561-5.

Davis DL, Hoel D, Fox J, Lopez A. (1990). International trends in cancer mortality in France, West Germany, Italy, Japan, England and Wales, and the United States. In: Davis DL, Hoel D, editors. Trends in cancer mortality in industrial countries. New York: The New York Academy of Sciences: 609:5-48.

Di Bisceglie AM. (1995). "Hepatitis C and hepatocellular carcinoma." Semin Liver Dis, 15:64-9.

Doll R. (2001). “The causes of cancer.” Rev Epidemiol Sante Publique, 49:193-200.

Easton A. (1999). "Liver cancer toll high in Japan.” BMJ, 318:1510.

Fujisawa T, Kumagai T, Akamatsu T, Kiyosawa K, Matsunaga Y. (1999). "Changes in seroepidemiological pattern of Helicobacter pylori and hepatitis A virus over the last 20 years in Japan.” Am J Gastroenterol, 94:2094-9.

Fukao A, Tsubono Y, Tsuji I, Hisamichi S, Sugahara N, Takano A. (1995). "The evaluation of screening for gastric cancer in Miyagi Prefecture, Japan: a population-based case-control study." Int J Cancer, 60:45-8.

Gao CM, Tajima K, Kuroishi T, Hirose K, Inoue M. (1993). "Protective effects of raw vegetables and fruit against lung cancer among smokers and ex-smokers: a casecontrol study in the Tokai area of Japan.” Jpn J Cancer Res, 84:594-600.

Greberman SB, Wada K. (1994). "Social and legal factors related to drug abuse in the United States and Japan." Public Health Rep, 109:731-7.

Gust ID. (1996). "Epidemiology of hepatitis B infection in the Western Pacific and South East Asia." Gut, 38:S18-23.

Hanai A, Benn T, Fujimoto I, Muir CS. (1988). "Comparison of lung cancer incidence rates by histological type in high and low incidence countries, with reference to the limited role of smoking." Jpn J Cancer Res, 79:445-52.

Hatano S. (1989). "Changing CHD mortality and its causes in Japan during 19551985." Int J Epidemiol, 18:S149-58.

Hirayama T. (1987). "The problem of smoking and lung cancer in Japan with special reference to the rising trend in age-specific mortality rate by number of cigarettes smoked daily." Jpn J Cancer Res, 78:203-10. 
Hirose K, Tajima K, Hamajima N, Takezaki T, Inoue M, Kuroishi T, Miura S, Tokudome S. (1999). "Effect of body size on breast-cancer risk among Japanese women." Int J Cancer, 80:349-55.

Hoel DG, Ron E, Carter R, Mabuchi K. (1993). "Influence of death certificate errors on cancer mortality trends." J Natl Cancer Inst, 85:1063-8.

Hoel DG, Wakabayashi T, Pike MC. (1983). "Secular trends in the distributions of the breast cancer risk factors-menarche, first birth, menopause, and weight-in Hiroshima and Nagasaki, Japan." Am J Epidemiol, 118:78-89.

Hoshi H, Kouchi M. (1981). "Secular trend of the age at menarche of Japanese girls with special regard to the secular acceleration of the age at peak height velocity." Hum Biol, 53:593-8.

Howe GR. (1994). Pancreatic cancer. In: Cancer incidence and mortality. Cancer surveys no. 19-20. Oxford: Oxford University Press: 139-58.

Howson CP, Hiyama T, Wynder EL. (1986). "The decline in gastric cancer: epidemiology of an unplanned triumph." Epidemiol Rev, 8:1-27.

Inaba S, Hirayama H, Nagata C, Kurisu Y, Takatsuka N, Kawakami N, Shimizu H. (1999). "Evaluation of a screening program on reduction of gastric cancer mortality in Japan: preliminary results from a cohort study." Prev Med, 29:1026.

Inoue M, Okayama A, Fujita M, Enomoto T, Tanizawa O, Ueshima H. (1994). "A casecontrol study on risk factors for uterine endometrial cancer in Japan." Jpn $J$ Cancer Res, 85:346-50.

International agency for research on cancer (IARC). (1986). "Screening for squamous cervical cancer: duration of low risk after negative results of cervical cytology and its implication for screening policies." Br Med J, 293:659-64.

- (1994). Schistosomes, liver flukes, and Helicobacter pylori. International agency for research on cancer (IARC) scientific publications no. 61. Lyon: IARC.

Ishimoto H, Nakamura H, Miyoshi T. (1994). "Epidemiological study on relationship between breast cancer mortality and dietary factors." Tokushima J Exp Med, 41:103-14.

Iso H, Shimamoto T, Naito Y, Sato S, Kitamura A, Iida M, Konishi M, Jacobs DR Jr, Komachi Y. (1998). "Effects of a long-term hypertension control program on stroke incidence and prevalence in a rural community in northeastern Japan." Stroke, 29:1510-8. 
Jablon S, Thompson D, McConney M, Mabuchi K. (1990). Accuracy of cause-of-death certification in Hiroshima and Nagasaki, Japan. In: Davis DL, Hoel D, editors. Trends in cancer mortality in industrial countries. New York: The New York Academy of Sciences: 609:100-9.

Japanese information network (JIN). (1999). "Births, deaths, life expectancy at birth, marriages, divorces, and cohabitation." Internet, http://jin.jcic.or.jp/stat/category_02.html.

Jernigan DH, Monteiro M, Room R, Saxena S. (2000). "Towards a global alcohol policy: alcohol, public health and the role of WHO." Bull World Health Organ, 78:491-9.

Kane MA. (1998). "Status of hepatitis B immunization programmes in 1998." Vaccine, 16:S104-8.

Kato H. (1986). Cancer mortality. In: Shigematsu I, Kagan A, editors. Cancer in atomic bomb survivors. Gann monograph on cancer research no. 32. Tokyo: Japan Scientific Societies Press: 53-74.

Kikuchi S. (2002). "Epidemiology of Helicobacter pylori and gastric cancer." Gastric Cancer, 5:6-15.

Kobayashi S. (1992). "Trends in national nutritional survey of Japan." Nutr Health, 8:91-6.

Kono S. (1996). Dietary factors for gastrointestinal cancers: a worldwide overview. In: Tajima K, Sonoda S, editors. Ethnoepidemiology of cancer. Gann monograph on cancer research no. 44. Tokyo: Japan Scientific Societies Press: 29-39.

Kono S, Ikeda M, Ogata M. (1983). "Salt and geographical mortality of gastric cancer and stroke in Japan." J Epidemiol Community Health, 37:43-6.

Kono S, Sunagawa Y, Higa H, Sunagawa H. (1990). "Age of menopause in Japanese women: trends and recent changes." Maturitas, 12:43-9.

Koo LC. (1997). "Diet and lung cancer 20+ years later: more questions than answers?" Int J Cancer, 10:22-9.

Kumagai T, Malaty HM, Graham DY, Hosogaya S, Misawa K, Furihata K, Ota H, Sei C, Tanaka E, Akamatsu T, et al. (1998). "Acquisition versus loss of Helicobacter pylori infection in Japan: results from an 8-year birth cohort study." J Infect Dis, 178:717-21. 
Kuroishi T, Tominaga S, Ota J, Horino T, Taguchi T, Ishida T, Yokoe T, Izuo M, Ogita M, Itoh S, et al. (1991). "The effect of mass screening for breast cancer: results of a multivariate analysis." Jpn J Cancer Res, 82:27-32.

Levi F, La Vecchia C, Negri E, Lucchini F. (1997). "Declining cancer mortality in European Union." Lancet, 349:508-9.

Levi F, Lucchini F, La Vecchia C, Negri E. (1999). "Trends in mortality from cancer in the European Union, 1955-94.” Lancet, 354:742-3.

Levin B. (1992). "Nutrition and colorectal cancer." Cancer, 70:1723-6.

Lin Y, Tamakoshi A, Wakai K, Kawamura T, Aoki R, Kojima M, Ohno Y. (1998). "Descriptive epidemiology of pancreatic cancer in Japan." J Epidemiol, 8:52-9.

Liver cancer study group of Japan (LCSGJ). (1987). "Primary liver cancer in Japan. Sixth report." Cancer, 60:1400-11.

- (1990). "Primary liver cancer in Japan. Clinicopathologic features and results of surgical treatment." Ann Surg, 211:277-87.

- (1995). Primary liver cancer in Japan. In: Watanabe S, Tominaga S, Kakizoe T, editors. Cancer treatment and survival: site-specific registries in Japan. Gann monograph on cancer research no. 43. Tokyo: Japan Scientific Societies Press: 81-95.

Lorber B. (1996). “Are all diseases infectious?” Ann Intern Med, 125:844-51.

Makimoto K, Higuchi S. (1999). "Alcohol consumption as a major risk factor for the rise in liver cancer mortality rates in Japanese men." Int J Epidemiol, 28:30-4.

Malaty HM, El-Kasabany A, Graham DY, Miller CC, Reddy SG, Srinivasan SR, Yamaoka Y, Berenson GS. (2002). "Age at acquisition of Helicobacter pylori infection: a follow-up study from infancy to adulthood." Lancet, 359:931-5.

Malaty HM, Kumagai T, Tanaka E, Ota H, Kiyosawa K, Graham DY, Katsuyama T. (2000). "Evidence from a nine-year birth cohort study in Japan of transmission pathways of Helicobacter pylori infection." J Clin Microbiol, 38:1971-3.

Mansell CJ, Locarnini SA. (1995). "Epidemiology of hepatitis C in the East." Semin Liver Dis, 15:15-32.

McLaughlin JR, Fields ALA, Gentleman JF, Levy I, Whylie B, Whittaker H, Riley R, Lee J, Coombs BA, Gaudette LA. (1997). "Cancer incidence and mortality, 1997." Health Rep, 8:41-51. 
Mendall MA, Goggin PM, Molineaux N, Levy J, Toosy T, Strachan D, Northfield TC. (1992). "Childhood living conditions and Helicobacter pylori seropositivity in adult life." Lancet, 339:896-7.

Minami Y, Takano A, Okuno Y, Fukao A, Kurihara M, Hisamichi S. (1996). "Trends in the incidence of female breast and cervical cancers in Miyagi Prefecture, Japan, 1959-1987." Jpn J Cancer Res, 87:10-7.

Ministry of health and welfare (MHW). (1951-1996). Japanese vital statistics 19511996. Tokyo: Kousei Tokei Kyokai.

-. (1989). Kokumin eiyo no genjo. Showa 62-nen Kokumin Eiyo Chosa Sei Seki.

—. (1990). Kokumin eiyo no genjo. Showa 62-nen Kokumin Eiyo Chosa Sei Seki.

—. (1998). Kokumin eiyo no genjo. Heisei 9-nen Kokumin Eiyo Chosa Kekka.

Mizuno S, Akiba S, Hirayama T. (1989). "Lung cancer risk comparison among male smokers between the "six-prefecture cohort" in Japan and the British physicians' cohort." Jpn J Cancer Res, 80:1165-70.

Morimoto T, Sasa M, Yamaguchi T, Kondo H, Sagara Y, Kuwamura Y, Yamamoto S, Tada T. (1997). "Effectiveness of mammographic screening for breast cancer in women aged over 50 years in Japan.” Jpn J Cancer Res, 88:778-84.

Moriyama M, Kashiwazaki H, Takemoto T, Suzuki T. (1977). "A secular trend in age at menarche in Sendai city and its surroundings." Tohoku J Exp Med, 123:393-4.

Muñoz N, Franceschi S. (1997). "Epidemiology of gastric cancer and perspectives for prevention." Salud Publica Mex, 39:318-30.

Murray CJL, Lopez AD, editors. (1996). The global burden of disease: a comprehensive assessment of mortality and disability from diseases, injuries, and risk factors in 1990 and projected to 2020. Global burden of disease and injury series, volume 1. Cambridge, MA: The Harvard School of Public Health.

Nakatsuka H, Ezaki H. (1986). Colorectal cancer among atomic bomb survivors. In: Shigematsu I, Kagan A, editors. Cancer in atomic bomb survivors. Gann monograph on cancer research no. 32. Tokyo: Japan Scientific Societies Press: 155-165.

National cancer institute (NCI). (1999). "Cancer death rates among 50 countries." Internet, http://rex.nci.nih.gov/NCI_Pub_Interface/raterisk/rates34.html. 
National institutes of health (NIH). (1997). "Consensus statement: national institutes of health consensus development conference statement on cervical cancer." Gynecol Oncol, 66:351-61.

Neugut AI, Hayek M, Howe G. (1996). "Epidemiology of gastric cancer." Semin Oncol, 23:281-91.

Nicolaides-Bouman A, Wald N, Forey B, Lee P, editors. (1993). International smoking statistics: a collection of historical data from 22 economically developed countries. London: Wolfson Institute of Preventive Medicine.

Ohno Y. (1985). "Health development in Japan: determinants, implications and perspectives." World Health Stat Q, 38:176-92.

Ohuchi N, Yoshida K, Kimura M, Ouchi A, Kamioki S, Shiiba KI, Matoba N, Kojima S, Takahashi K, Matsuno S, et al. (1993). "Improved detection rate of early breast cancer in mass screening combined with mammography." Jpn J Cancer Res, 84:807-12.

Olshansky SJ, Ault AB. (1986). "The fourth stage of the epidemiologic transition: the age of delayed degenerative diseases." Milbank Q, 64:355-91.

Olshansky SJ, Carnes BA. (2001). The quest for immortality: science at the frontiers of aging. New York: WW Norton and Company.

Olshanksy SJ, Carnes BA, Rogers RG, Smith L. (1997). "Infectious diseases-new and ancient threats to world health." Pop Bull, 52:33.

Omran AR. (1971). "The epidemiologic transition: a theory of the epidemiology of population change." Milbank Mem Fund Q, 49:509-38.

Parkin DM, Muir CS, Whelan SL, Gao YT, Ferlay J, Powell J, editors. (1992). Cancer incidence in five continents, volume 6. International agency for research on cancer (IARC) scientific publications no. 120. Lyon: IARC.

Parkin DM, Pisani P, Lopez AD, Masuyer E. (1994). "At least one in seven cases of cancer is caused by smoking. Global estimates for 1985." Int J Cancer, 59:494504.

Parkin DM, Whelan SL, Ferlay J, Raymond L, Young J, editors. (1997). Cancer incidence in five continents, volume 7. International agency for research on cancer (IARC) scientific publications no. 143. Lyon: IARC. 
Parrish KM, Higuchi S, Muramatsu T, Stinson FS, Harford TC. (1991). "A method for estimating alcohol-related liver cirrhosis mortality in Japan." Int J Epidemiol, 20:921-6.

Pierce DA, Shimizu Y, Preston DL, Vaeth M, Mabuchi K. (1996). "Studies of the mortality of atomic bomb survivors. Report 12, part I. Cancer: 1950-1990." Radiat Res, 146:1-27.

Pisani P, Parkin DM. (1996). Screening for gastric cancer. In: Miller AB, editor. Advances in cancer screening. Boston: Kluwer Academic Publishers: 113-119.

Pisani P, Parkin DM, Muñoz N, Ferlay J. (1997). "Cancer and infection: estimates of the attributable fraction in 1990." Cancer Epidemiol Biomarkers Prev, 6:387400 .

Population reference bureau (PRB). (2000). World population data sheet. Washington, DC: Population Reference Bureau.

Potter JD. (1996). "Nutrition and colorectal cancer." Cancer Causes Control, 7:127-46.

Replogle ML, Kasumi W, Ishikawa KB, Yang SF, Juji T, Miki K, Kabat GC, Parsonnet J. (1996). "Increased risk of Helicobacter pylori associated with birth in wartime and post-war Japan." Int J Epidemiol, 25:210-4.

Rogers RG, Hackenberg R. (1987). "Extending epidemiologic transition theory: a new stage." Soc Biol, 34:234-43.

Sato S, Matsunaga G, Konno R, Yajima A. (1998). "Mass screening for cancer of the endometrium in Miyagi Prefecture, Japan." Acta Cytol, 42:295-8.

Shimotohno K. (1996). Hepatitis C virus and hepatocellular carcinoma. In: Tajima K, Sonoda T, editors. Ethnoepidemiology on cancer. Gann monograph on cancer research no. 44. Tokyo: Japan Scientific Societies Press: 149-158.

Sobue T, Suzuki T, Fujimoto I, Matsuda M, Doi O, Mori T, Furuse K, Fukuoka M, Yasumitsu T, Kuwahara O, et al. (1991). "Lung cancer risk among exsmokers." Jpn J Cancer Res, 82:273-9.

Sonoda T, Yamaguchi N. (1995). Registration of gynecologic malignancies. In: Watanabe S, Tominaga S, Kakizoe T, editors. Cancer treatment and survival: site-specific registries in Japan. Gann monograph on cancer research no. 43. Tokyo: Japan Scientific Societies Press: 169-180.

Stuver SO, Trichopoulos D. (1994). Liver cancer. In: Cancer incidence and mortality. Cancer surveys no. 19-20. Oxford: Oxford University Press: 99-124. 
Swinbanks D. (1989). "Hepatitis viruses. Blood donors to be screened." Nature, 342:467.

Tanaka K, Hirohata T, Takeshita S, Hirohata I, Koga S, Sugimachi K, Kanematsu T, Ohryohji F, Ishibashi H. (1992). "Hepatitis B virus, cigarette smoking and alcohol consumption in the development of hepatocellular carcinoma: a casecontrol study in Fukuoka, Japan." Int J Cancer, 51:509-14.

Tanaka H, Tanaka Y, Hayashi M, Ueda Y, Date C, Baba T, Shoji H, Horimoto T, Owada K. (1982). "Secular trends in mortality for cerebrovascular diseases in Japan, 1960 to 1979." Stroke, 13:574-81.

Thom TJ. (1993). "Stroke mortality trends: an international perspective." Ann Epidemiol, 3:509-18.

Tominaga S, Kuroishi T. (1995). "Epidemiology of breast cancer in Japan." Cancer Lett, 90:75-9.

—. (1998). "Epidemiology of pancreatic cancer." Semin Surg Oncol, 15:3-7.

Tominaga S, Oshima A, editors. (1999). Cancer mortality and morbidity statistics: Japan and the world, 1999. Gann monograph on cancer research no. 47. Tokyo: Japan Scientific Societies Press.

Tung HT, Tsukuma H, Tanaka H, Kinoshita N, Koyama Y, Ajiki W, Oshima A, Koyama H. (1999). "Risk factors for breast cancer in Japan, with special attention to anthropometric measurements and reproductive history." Jpn J Clin Oncol, 29:137-46.

Uemura N, Okamoto S, Yamamoto S, Matsumura N, Yamaguchi S, Yamakido M, Taniyama K, Sasaki N, Schlemper RJ. (2001). "Helicobacter pylori infection and the development of gastric cancer." N Engl J Med, 345:784-9.

Veldhuyzen van Zanten SJO, Pollak PT, Best LM, Bezanson GS, Marrie T. (1994). "Increasing prevalence of Helicobacter pylori infection with age: continuous risk of infection in adults rather than cohort effect." J Infect Dis, 169:434-7.

Wada K. (1994). “Cocaine abuse in Japan.” Jpn J Alcohol Drug Dependence, 29:83-91.

Wakai K, Suzuki S, Ohno Y, Kawamura T, Tamakoshi A, Aoki R. (1995). "Epidemiology of breast cancer in Japan." Int J Epidemiol, 24:285-91.

Weisburger JH. (1997). "Dietary fat and risk of chronic disease: mechanistic insights from experimental studies." J Am Diet Assoc, 97:S16-23. 
Wilmink AB. (1997). "Overview of the epidemiology of colorectal cancer." Dis Colon Rectum, 40:483-93.

Wilmoth JR. (1995). "Are mortality projections always more pessimistic when disaggregated by cause of death?" Math Popul Stud, 5:293-319.

—. (2002). "Human mortality database." Internet, http://www.mortality.org.

Wilmoth JR, Lundström H. (1996). "Extreme longevity in five countries: presentation of trends with special attention to issues of data quality." Eur J Popul, 12:63-93.

Wingo PA, Ries LAG, Giovino GA, Miller DS, Rosenberg HM, Shopland DR, Thun MJ, Edwards BK. (1999). "Annual report to the nation on the status of cancer, 1973-1996, with a special section on lung cancer and tobacco smoking." J Natl Cancer Inst, 91:675-90.

World health organization (WHO). (1992). ICD-10: international statistical classification of diseases and related health problems. Geneva: World Health Organization.

- . (1996). The world health report 1996: fighting disease, fostering development. Geneva: World Health Organization.

—. (1997a). "Hepatitis C: global prevalence.” Wkly Epidemiol Rec, 72:341-4.

-. (1997b). Tobacco or health: a global status report. Geneva: World Health Organization.

Wynder EL, Taioli E, Fujita Y. (1992). "Ecologic study of lung cancer risk factors in the U.S. and Japan, with special reference to smoking and diet." Jpn J Cancer Res, 83:418-23.

Yanagishita M, Guralnik JM. (1988). "Changing mortality patterns that led life expectancy in Japan to surpass Sweden's: 1972-1982." Demography, 25:611-24.

Yoshiike N, Matsumura Y, Iwaya M, Sugiyama M, Yamaguchi M. (1996). "National nutrition survey in Japan." J Epidemiol, 6:S189-200.

Zimmer C. (2001). "Do chronic diseases have an infectious root?" Science, 293:1974-7. 